\title{
A Note on Conventions
}

All place names, personal names, and Chinese terms are rendered in pinyin. Dates are given according to the Chinese calendar in the following manner: QL 35.5.3 (1770). The reign periods of the Qing emperors are abbreviated as follows:

$\begin{array}{llll}\text { Shunzhi (SZ) } & \text { I644-6I } & \text { Daoguang (DG) } & \text { I 82 I-50 } \\ \text { Kangxi (KX) } & \text { I662-I722 } & \text { Xianfeng (XF) } & \text { I 85I-6I } \\ \text { Yongzheng (YZ) } & \text { I723-35 } & \text { Tongzhi (TZ) } & \text { I 862-74 } \\ \text { Qianlong (QL) } & \text { I736-95 } & \text { Guangxu (GX) } & \text { I 875-I908 } \\ \text { Jiaqing (JQ) } & \text { I796-I820 } & \text { Xuantong (XT) } & \text { I909-I I }\end{array}$




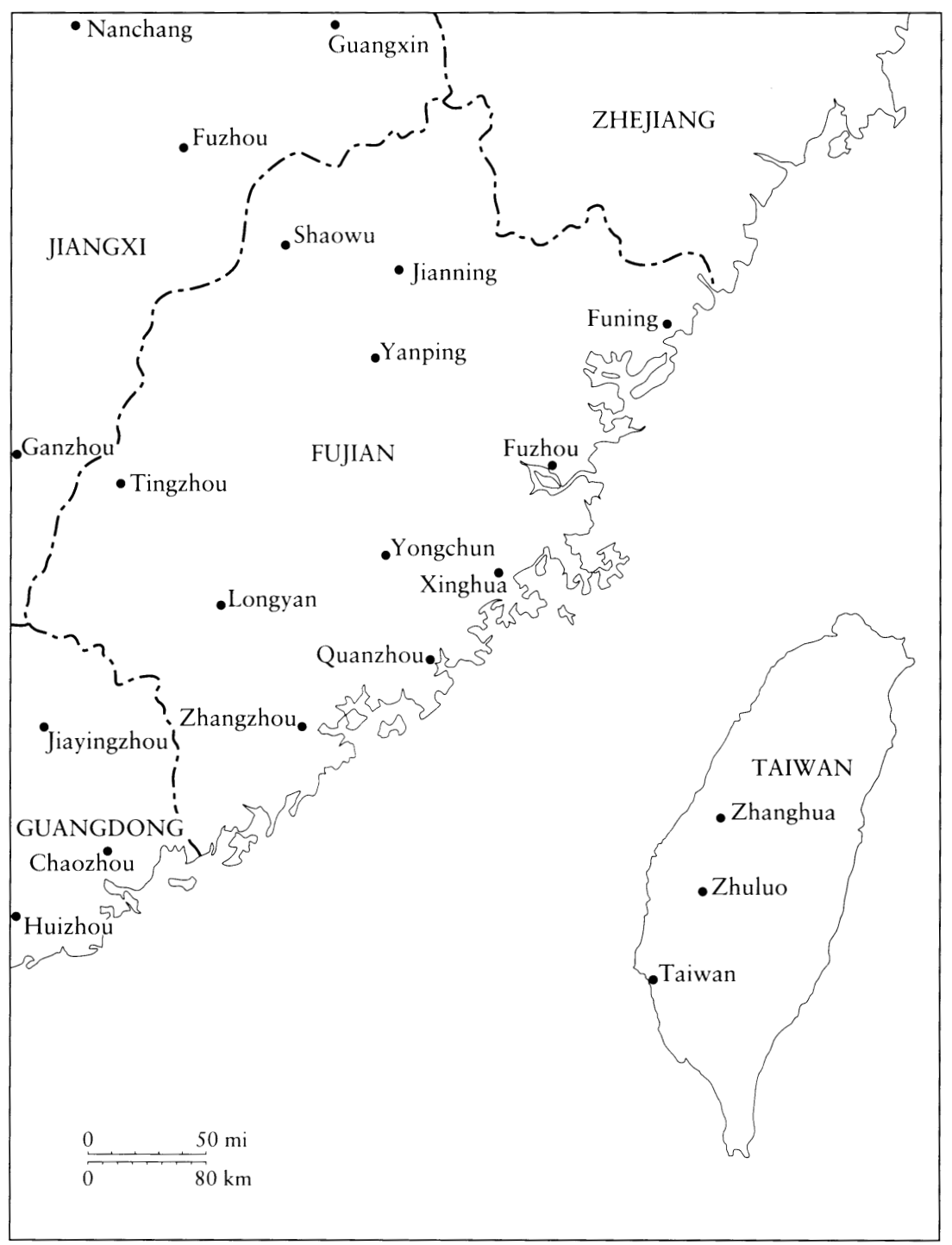

Map I. Taiwan and adjoining areas of Southeast China 
Brotherhoods and Secret Societies in Early and Mid-Qing China 
